\title{
Criminal Violations of Environmental Laws: Model Sentencing Guidelines \$2E1
}

Michael M. O'Hear

Marquette UniversityLaw School, michael.ohear@marquette.edu

Follow this and additional works at: http://scholarship.law.marquette.edu/facpub

Part of the Law Commons

Publication Information

Published as Michael M. O’Hear, Criminal Violations of Environmental Laws: Model Sentencing Guidelines $\$ 2 E 1,18$ Fed. Sent'g Rep. 341 (2006). (C) 2006 by the Regents of the University of California on behalf of the Vera Institute of Justice. Copying and permissions notice: Authorization to copy this content beyond fair use (as specified in Sections 107 and 108 of the U. S. Copyright Law) for internal or personal use, or the internal or personal use of specific clients, is granted by the Regents of the University of California on behalf of the Vera Institute of Justice for libraries and other users, provided that they are registered with and pay the specified fee via Rightslink ${ }^{\circledast}$ on Caliber (http://caliber.ucpress.net/) or directly with the Copyright Clearance Center, http://www.copyright.com.

\section{Repository Citation}

O'Hear, Michael M., "Criminal Violations of Environmental Laws: Model Sentencing Guidelines \$2E1" (2006). Faculty Publications. Paper 110.

http://scholarship.law.marquette.edu/facpub/110 


\section{Criminal Violations of Environmental Laws: \\ Model Sentencing Guidelines §2E1}

\section{Model Sentencing Guidelines §2E1 Environmental Crimes}

(a) Base Offense Level: The base offense level for all offenses covered by this guideline is $\mathbf{I}$.

(b) Specific Offense Characteristics

(I) Harmfulness: If the offense conduct resulted in an unreasonable risk of:

(A) Any harm to the environment add I

(B) Aggravated harm to the environment add 2

(C) Catastrophic harm to the environment or the imminent death or imminent serious bodily injury of one person add 3

(D) Imminent death or imminent serious bodily injury of at least five people add 4

(E) Imminent death or imminent serious bodily injury of at least twenty-five people

(2) Elevated Risk and Aggravated Mens Rea: If the offense level was enhanced under Subsection (b)(I) above, increase the offense level by an additional one level if the applicable harm (as described in (b)(I)(A), (B), (C), (D), or (E)) was practically certain to result from the offense conduct and the defendant knew that this harm was practically certain to occur.

(3) Death: If the offense conduct resulted in the death of at least one person, add one level.

(c) Advisory Factors to be considered in setting the sentencing within the applicable range

In determining the position of a sentence within the applicable range, the court should consider whether any of the following factors exist:

(I) Aggravating Factors:

(A) The offense conduct resulted in actual harm of any type, as opposed to the mere risk of harm (except that the actual harm of death is separately accounted for in Subsection (b)(3) above);

(B) The offense conduct created risks of harm that, either in kind or degree, are not adequately accounted for in the determination of the sentencing range;

(C) The offense conduct occurred on more than one occasion;
(D) The offender has previously been subject to an administrative sanction or civil judgment in connection with an earlier environmental violation;

(E) The offense constituted a violation of a judicial or administrative order;

(F) The offense constituted a violation of a permit or a knowing failure to obtain a permit;

(G) The offender took affirmative steps to conceal the offense or failed to comply with a legal obligation to report the offense or environmental contamination resulting from the offense;

(H) If an enhancement under Subsection (b)(I) was applied based on an unreasonable risk of harm, but there was no enhancement under Subsection (b)(2), and the offender acted in conscious disregard of the risk;

(I) The offender's purpose was to cause harm to human health or the environment.

(2) Mitigating Factors:

(A) The offender had a good-faith belief, based on a mistake of law or fact, that the offense conduct was not prohibited by law;

(B) The offender exceeded the minimal requirements of the law in reporting or responding to the offense conduct so as to minimize any risks of harm;

(C) No harm was actually caused, or any harm was limited to the offender's own property or business.

\section{Application Notes:}

DEFINITIONS: An "unreasonable risk" is a substantial and unjustifiable risk. The risk must be of such a nature and degree that the offender's conduct giving rise to the risk constitutes a gross deviation from the standard of care that a reasonable person would observe in the offender's situation, taking into account the nature and purpose of his conduct and the circumstances known to him.

A "harm to the environment" is any type of lasting, measurable degradation of air, water, or soil quality; death of a legally protected wild plant or animal; exposure of any person

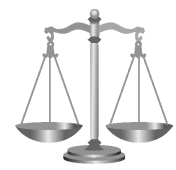

MICHAEL M. O'HEAR

Associate Professor, Marquette University Law School

Editor, Federal Sentencing Reporter 
to a regulated substance in such a quantity and in such circumstances as are likely to cause a bodily injury or to increase significantly the person's risk of contracting a fatal or disabling medical condition in the future; or disruption of a public utility.

An "aggravated harm to the environment" is an environmental harm that substantially, adversely affects a sizeable area of land or water, in terms of its ability to support plant or animal life, or its ability to be used by humans for commercial or recreational purposes. The smaller the area affected (e.g., just one acre of land), the more serious the degradation would have to be in order to qualify. The term also includes the death of a substantial number of plants or animals (taking into consideration the rarity, ecological significance, and legal status of the species involved); exposure of at least five people to a regulated substance in such a quantity and in such circumstances as are likely to cause bodily injury or to increase significantly the risk of contracting a fatal or disabling medical condition in the future; or a major, short-term disruption of human activities, such as the evacuation of a neighborhood.

A "catastrophic harm to the environment" is an aggravated environmental harm that, based on its unusual duration; intensity; geographical scope; number of people, plants, or animals affected; and/or ecological or economic costs, is of such an extreme nature that it can fairly be termed a "catastrophe."

The term includes the exposure of at least twenty-five people to a regulated substance in such a quantity and in such circumstances as are likely to cause bodily injury or to increase significantly the risk of contracting a fatal or disabling medical condition in the future. The term also includes comparably severe, long-term disruptions to ecosystems or human communities, such as the filling-in of hundreds of acres of wetlands, or the contamination of a community's water supply, such that the community would have to obtain water from alternative sources at considerably greater expense for an indefinite period of time.

\section{DRAFTER'S COMMENTARY}

\section{General Approach}

This Model Guideline covers the offenses now governed by U.S.S.G. $\iiint_{2}$ QI.I, 2QI.2, and 2QI.3. It is premised on the view that, in sentencing an environmental offender, three considerations should predominate: (I) harm (the magnitude of injury that was threatened by the offender's conduct), (2) danger (the likelihood that the harm would actually come about), and (3) mens rea (the offender's state of mind with respect to the harm). ${ }^{\mathrm{I}}$ In general, this view is philosophically consistent with the existing guidelines, particularly in its emphasis on harm and danger. (The existing guidelines give comparatively less attention to mens rea but do not wholly disregard that factor, either.)

Environmental crime differs from most other sorts of crime in the extraordinary range of potential harm, both in terms of kind and degree. For instance, theft and fraud crimes will all involve the harm of property loss. Environ- mental crimes also sometimes involve property loss, as when a victim's property loses market value due to groundwater contamination. In other cases, however, the harm will be to wildlife, air, or bodies of water that are not any person's property but rather public goods. The available means of translating these sorts of harms into pecuniary terms, as is common for purposes of sentencing most property crimes, are both unusually complex and not wholly satisfactory from a theoretical standpoint. In still other cases, the principal harm will be to human health. Health-related harms cover a vast range, from the immediate and dramatic (e.g., severe burns over much of a victim's body), to the immediate and minor (e.g., a temporary rash over a small portion of a victim's body), to the possibility of long-term consequences that may or may not ever materialize (e.g., the possibility of contracting lung disease as a result of asbestos exposure). Finally, some cases present, at most, so-called regulatory harms-for example, the inconvenience and expense that may be imposed on regulatory agencies as a result of record-keeping violations. The unusual range of harms encompassed by environmental cases presents important challenges in drafting an environmental sentencing guideline.

In order to deal with these challenges, the existing guidelines employ a seemingly ad hoc array of specific, overlapping indicia of harm and danger, with considerable risk of both over- and undercounting the true severity of the offense. ${ }^{2}$ The proposed guideline instead employs a small number of broadly defined, flexible categories. This approach is better suited both to the diverse nature of environmental crimes and to the need to minimize the number of decision points for the jury.

Some may be uncomfortable with the use of imprecise, qualitative language to define the categories. (For instance, the boundaries of what constitutes a "catastrophe" are not objectively ascertainable in any precise way.) This will undoubtedly entail some uniformity costs, as different juries apply the language in different ways. On the other hand, it is easy to overestimate the uniformity benefits of seemingly more objective specific offense characteristics ("SOCs"), which, for instance, are readily manipulable through the plea-bargaining process ${ }^{3}$ and often themselves contain subtle ambiguities. ${ }^{4}$ Moreover, given both the unusually diverse nature of environmental harms and the need for simplified guidelines with only a limited number of SOCs for jury consideration, it is far from clear what set of "objective" SOCs would provide a satisfactory means of distinguishing more from less serious environmental crimes. Guidelines that fail to make important distinctions among cases achieve, at best, only a false uniformity.

Finally, it is important to recognize that environmental cases are relatively few in number, averaging little more than one per district per year. ${ }^{5}$ In comparison with other sorts of cases that crowd the federal docket, such as drug, gun, and immigration cases, uniformity is a rather less compelling value in the environmental context. When 
similarly situated environmental offenders are sentenced differently, the disparity will be less clear to the public and to the offenders themselves; indeed, given the relatively small number of environmental offenders, there are not likely many sets of such offenders who are similarly situated in any obvious way. ${ }^{6}$ Rather than undertaking a quixotic pursuit of strict uniformity in this context, it is preferable to implement a set of guidelines that invite principled discussion and deliberations about the true moral significance of the offender's misconduct-this is the better path to assuring offenders and the public that sentences are not arbitrary.?

\section{Specific Offense Characteristics}

\section{A. Nature and Degree of Risk}

The SOCs combine considerations of harm, danger, and mens rea. The threshold requirement for any enhancement (other than the enhancement for death) is that the offense conduct created an unreasonable risk. This requirement is intended to correspond to the culpability level of "criminal negligence" in the Model Penal Code. For purposes of the SOCs, it is neither necessary nor sufficient that some environmental harm has actually come to pass; rather, risk is the touchstone of the analysis. This is consistent with the basic risk-management thrust of modern environmental law.

Not all risk qualifies for an enhancement, however; the risk must be "unreasonable." Reasonability is, in part, a function of the likelihood that the risked harm will actually come to pass, but there is no magic percentage threshold (e.g., more likely than not). The nature and degree of the harm, as well as the attendant circumstances, may bear upon the reasonability determination.

\section{B. Severity of Harm}

Once it is determined that the offender has created an unreasonable risk, the next step is to determine the severity of the harm that was risked, which may result in an enhancement of between one and five levels. The three most severe categories of harm, however, will only rarely be implicated, meaning that the jury will really just have two decision points in most cases: whether there was a risk of "environmental harm" and, if so, whether that harm was an "aggravated" one.

The "any environmental harm" SOC is not intended to set a high bar. It should be routinely satisfied in cases that arise from a nontrivial discharge of regulated substances. Thus, for instance, a chemical spill that measurably contaminates even one cubic yard of soil would qualify, assuming the contamination is not ephemeral in nature.

An environmental harm may rise to the "aggravated" level based on any of a number of different considerations. For instance, if the environmental harm SOC is satisfied on the basis of degradation of air, water, or soil quality, the harm might be appropriately determined "aggravated" based on the severity of the degradation and the quantity of air, water, or soil affected. These considerations ought to be assessed in light of the prior ecological and social value of the affected area. Thus, contamination of one acre of a small but popular urban park might count as aggravated, while contamination of ten acres of land that is barren and isolated might not. If, by way of further example, the environmental harm SOC is satisfied on the basis of injury to plant or animal life, the harm might be appropriately determined "aggravated" based on the number of plants and animals affected. Once again, there is no universal numerical cutoff; rather, the number must be assessed in light of the ecological and social value of the affected plants and animals. ${ }^{8}$ Because these sorts of standards are necessarily imprecise, it may be helpful for the jury to consider as a benchmark other, somewhat more objective prongs of the definition of "aggravated environmental harm," such as the evacuation of a neighborhood or the imposition of nonserious bodily injuries on at least five people.

Each of the categories of environmental harm encompasses a wide range of severity. If the severity of the harm in a given case is at the low end within the category, then that fact ought to be considered as mitigating by the judge when selecting a sentence within the applicable range. Likewise, if the severity of harm is at the high end, then that fact ought to be considered as aggravating.

Few environmental cases involve an imminent risk of death or serious bodily injury to a human being. In such cases, however, the nature of the harm merits a categorically more severe sentence. While some might question the per se elevation of human over environmental harm, this approach is consistent with the relevant statutory schemes. 9 For purposes of making distinctions within this aggravated category, a quantitative approach is employed: different offense levels apply depending on the number of people affected. ${ }^{\mathrm{IO}}$ The difficulty lies in drawing the specific cutoff points. There is admittedly some arbitrariness in a guideline that treats risks imposed on four people as categorically different than risks imposed on five, but does not make a similar per se distinction as between risks imposed on five and six. It is expected, however, that the "cliffs" will be smoothed by the selection of sentences within the applicable range. For instance, cases involving a risk of death to four people should generally be sentenced near the top of the range, while cases involving a risk of death to five should generally be sentenced near the bottom of the higher range. The proposed sentencing ranges are wide enough to permit appropriate distinctions within categories, ${ }^{\text {II }}$ taking into consideration the basic principle that risks imposed on incremental individuals from a single act or course of conduct should generally result in decreasing marginal sentence enhancements. ${ }^{\text {I2 }}$

"Imminence" is, of course, an imprecise term, but one as to which there is a rich history of jury interpretation and implementation. ${ }^{13}$ It is, moreover, a concept embedded in the existing environmental guidelines. ${ }^{14}$ At the same time, the notion of imminent harm is arguably a 
poor fit with environmental crimes, which more typically impose long-term risks of harm. Here, long-term risks to human health are captured under the umbrella of "environmental harm," while imminent risks of death or serious bodily injury to five or more people are treated as categorically more serious. This is consistent with the basic principle of discounting: injuries suffered today are viewed as more serious than injuries suffered next year. ${ }^{15}$ Of course, the fact that a threatened, but not quite imminent, injury is almost certain to occur eventually may be considered an aggravating circumstance for purposes of selecting a sentence within the range.

\section{Aggravated Dangerousness and Mens Rea}

If the offense level is enhanced under Subsection (b)(I) based on an unreasonable risk of harm, then the offense level might be further enhanced under (b)(2) based on an elevated risk level (dangerousness) and an aggravated mens rea. If the offender knew not only that the offense conduct created a risk of harm but also that the harm was practically certain to occur, then the offense level should be increased by I. The culpability standard corresponds with the "knowledge" standard of the Model Penal Code. If the offender was merely reckless, an intermediate level of culpability in the Model Penal Code scheme between negligence and knowledge, then that fact might be considered an aggravating factor in selecting a sentence within the range.

Likewise, if the offender acted with the purpose of causing harm, then that fact might also be considered aggravating.

\section{Other Aggravating and Mitigating Factors}

The remaining aggravating factors in Subsection (c)(I) relate to (I) the extent of harm that actually came to pass as a result of the offense conduct; (2) the willfulness of the underlying environmental violation, in the sense that the requirements of the law should have been clear to the offender and/or the importance of environmental compliance had been impressed on the offender in prior judicial or administrative proceedings; and (3) concealment of the violation (assuming there is no separate enhancement for obstruction of justice). At first blush, it might seem odd that the guideline treats risk of harm as a primary consideration that may go to the jury, while giving actual harm a secondary role as a factor to be used in selecting a sentence within the range. This reflects the realities of the environmental context, however, in which the harmful consequences of a violation may unfold with sufficient slowness that they are impossible to assess fully at the time of sentencing, or are prevented from occurring as a result of timely intervention by the authorities or other fortuities. Either way, a primary focus on actual harm may result in sentences that do not adequately reflect the dangerousness of the offense conduct. ${ }^{\mathrm{I}}$

The mitigating factors in Subsection (c)(2) recognize that, while environmental crimes are often strict liability crimes, it is appropriate to distinguish for sentencing purposes (even if not for guilt-innocence purposes) between offenders who have acted in good faith and offenders who have not. Environmental laws are notoriously complicated, and, in at least some cases, offenders may be able to make a persuasive showing that they genuinely believed they were acting in a lawful manner and that their culpability was thus relatively low. (Of course, such a showing will be considerably easier in no- and low-danger than in high-danger cases.) Likewise, if an offender takes steps after a violation to minimize the risk of harm, particularly to the extent that such steps exceed what the law requires, such action also reflects good faith and suggests that the violation may have been inadvertent. Furthermore, treating such conduct as mitigating provides offenders with an incentive to undertake socially desirable risk-minimizing responses.

\section{Severity}

The severity level of the guideline is generally consistent with the severity level of the existing guidelines. Some representative comparisons are indicated in Table I. For instance, under the existing law (specifically, $\mathbb{8}$ 2Qı.2(b)(6)), a simple record-keeping violation would produce an offense level of 6 and a term of zero to six months. (All of the examples here assume Criminal History Category I.) Because a simple record-keeping violation would probably never involve an unreasonable risk of harm, the offense would produce an offense level of I and, again, a term of zero to six months under the proposed guideline.

\section{Table 1. Comparison of Severity of Existing and Proposed Guidelines}

\begin{tabular}{lcc}
\hline & Existing Guidelines & Proposed Guideline \\
\hline $\begin{array}{l}\text { Record-keeping } \\
\text { violation }\end{array}$ & $0-6$ mos. & 0-6 mos. \\
$\begin{array}{l}\text { Toxic discharge: } \\
\text { likelihood of death }\end{array}$ & $37-46$ mos. & $24-60$ mos. \\
$\begin{array}{l}\text { Knowledge of } \\
\text { imminent death } \\
\text { Repeated, } \\
\text { nontoxic discharge }\end{array}$ & $5 \mathrm{I}-63$ mos. & $60-96$ mos. \\
\hline
\end{tabular}

At the opposite end of the spectrum, a toxic discharge resulting in a substantial likelihood of death would produce an offense level of 2I and a term of thirty-seven to forty-six months under the applicable existing guideline (2Q1.2(b)(I)(B), (2)). These facts would likely satisfy the requirements of the unreasonable risk of imminent death or serious bodily injury SOC (Subsection (b)(I)(C)) under the proposed guideline, which would produce an offense level of at least 4 and a term of two to five years (or twentyfour to sixty months).

Under the existing guidelines, an offense committed with knowledge that the violation placed another person in imminent danger of death would produce an offense level of 24 and a term of fifty-one to sixty-three months (2QI.I). Under the proposed guideline, an offense committed with knowledge that imminent death was practically certain (a slightly higher mens rea) would produce an offense level 
of 5 and a term of five to eight years (or sixty to ninety-six months).

Under the existing guideline, a more routine sort of discharge violation, say, a repeated discharge of a nontoxic pollutant in violation of a permit, would produce an offense level of $\mathrm{I} 6$ and a term of twenty-one to twentyseven months (2QI.3(b)(I), (4)). Assuming that these facts would typically be associated with a practical certainty of some harm to the environment, then the proposed guideline would produce an offense level of 3 and a term of twelve to twenty-four months. If the harm were practically certain to be aggravated, as might be the case without triggering any further enhancements under the existing guideline, then the proposed guideline would produce an enhanced range of twenty-four to sixty months.

\section{Notes}

1 For a more detailed description and defense of this basic approach, see Michael M. O'Hear, Sentencing the Green-Collar Offender: Punishment, Culpability, and Environmental Crime, 95 J. CRIM. L. \& CRIMInology 133 (2004).

2 See, e.g., id. at 226 (observing that a "one-time non-toxic discharge in violation of a permit that results in the need for substantial cleanup expenditures, but does not create any real likelihood of physical injury" may result in a higher offense level than an environmental violation resulting in a substantial likelihood of death).

3 Michael M. O'Hear, The Myth of Uniformity, 17 Fed. Sent'ing Rptr. 249, 253 (2005).

4 See, e.g., O'Hear, supra note 1, at 231-35 (discussing SOCs in existing environmental guidelines that have generated appel. late litigation).

5 Id. at 205.

6 Congress adopted uniformity as a dominant goal of the fed. eral system because of concerns that public and offender perceptions of disparity were casting the system into disrepute and undermining deterrence objectives. Michael M. O'Hear, The Original Intent of Uniformity in Federal Sentencing, U. CIN. L. REV. 749, 773, 791.93 (2006). It follows that invisible disparities, i.e., disparities that are not perceived by the public or offenders, should not be viewed as objectionable to quite the same degree as patent disparities.

7 Disparities, moreover, may be diminished over time as appel. late courts develop a body of case law elaborating on the basic principles articulated in the guidelines. Appellate decisions may contribute to the development of more specific jury instructions, as well as guidance that district court judges may use to identify jury sentencing decisions that are not adequately supported by the evidence.

8 These considerations may require jury deliberation on ecolog. ical questions. This may complicate the sentencing process but should not present any intrinsically greater difficulty than jury decision making on other questions that often involve expert testimony, such as loss calculations in securities fraud and tax cases.

9 See O'Hear, supra note 1, at 143 (noting that environmental statutes typically provide maximum sentences of only three to five years for knowing violations, but up to fifteen years for violations that place individuals in imminent danger of death or serious bodily injury).

10 This contrasts with the qualitative approach taken to ranking environmental harms. As indicated above, a qualitative approach is appropriate for environmental harms because such harms are unusually rich in their variety and complexity. Thus, for instance, it would be a mistake to treat the contamination of one acre of land as categorically more serious than the contamination of five; we readily recognize that different parcels of land may have dramatically different ecological and economic value for reasons unrelated to their relative size. (Think, for instance, of the relative seriousness of contaminating one acre of Central Park versus five acres of unused farmland.) On the other hand, we are generally quite reluctant to assert that any one human life has more value than any other. It makes more sense, then, to employ quantitative distinctions with respect to the most severe human health harms; we can comfortably say that risking the death of five people is per se more serious than risking the death of one.

11 An offense involving an unreasonable risk of imminent death or serious bodily injury to multiple individuals will result in an offense level of at least 4 , which would translate into a range of at least two to five years. This would permit, for instance, the sentence for an offender who imposed an unreasonable risk of death on three or four people to be more than double the sentence for an offender who imposed such a risk on only one.

12 Stephen Breyer, The Federal Sentencing Guidelines and the Key Compromises upon Which They Rest, 17 Hofstra L. ReV. 1, 25. 26 (1988).

13 See, e.g., State v. Norman, 378 S.E.2d 8 (N.C. 1989) (discussing imminence requirement for defense of self-protection).

14 United States Sentencing Guidelines Manual $\S 2 \mathrm{Q} 1.1$, com. ment. (backg'd.) (2004).

15 For a salient discussion of discounting, see Richard L. Revesz, Environmental Regulation, Cost-Benefit Analysis, and the Discounting of Human Lives, 99 Colum. L. REV. 941, 950. 55 (1999).

16 O'Hear, supra note 1 , at 258-59. 